\title{
Associations of maternal age at the start of pregnancy with placental function throughout pregnancy: The Generation R Study
}

\author{
Jan S. Erkamp ${ }^{a, b}$, Vincent W.V. Jaddoe ${ }^{a, b}$, Annemarie G.M.G.J. Mulders ${ }^{c}$, \\ Liesbeth Duijts $^{\mathrm{a}, \mathrm{d}, \mathrm{e}}$, Irwin K.M. Reiss ${ }^{\mathrm{a}, \mathrm{d}}$, Eric A.P. Steegers ${ }^{\mathrm{c}}$, Romy Gaillard ${ }^{\mathrm{a}, \mathrm{b}, *}$ \\ ${ }^{a}$ The Generation R Study Group, Erasmus MC, University Medical Center Rotterdam, Rotterdam, the Netherlands \\ b Department of Pediatrics, Erasmus MC, University Medical Center Rotterdam, Rotterdam, the Netherlands \\ ${ }^{\mathrm{c}}$ Department of Obstetrics \& Gynecology, Erasmus MC, University Medical Center Rotterdam, Rotterdam, the Netherlands \\ d Department of Pediatrics, Division of Neonatology, Erasmus MC, University Medical Center Rotterdam, Rotterdam, the Netherlands \\ e Department of Pediatrics, Division of Respiratory Medicine and Allergology, Erasmus MC, University Medical Center Rotterdam, Rotterdam, the Netherlands
}

\section{A R T I C L E IN F O}

\section{Article history:}

Received 2 March 2020

Received in revised form 23 April 2020

Accepted 24 April 2020

Available online $\mathrm{xxx}$

\section{Keywords:}

Maternal age

Placental function

Doppler

Uterine artery

Resistance index

\begin{abstract}
A B S T R A C T
Objective: To examine the associations of maternal age at the start of pregnancy across the full range with second and third trimester uterine and umbilical artery flow indices, and placental weight.

Study design: In a population-based prospective cohort study among 8271 pregnant women, we measured second and third trimester uterine artery resistance and umbilical artery pulsatility indices and the presence of third trimester uterine artery notching using Doppler ultrasound.

Results: Compared to women aged 25-29.9 years, higher maternal age was associated with a higher third trimester uterine artery resistance index (difference for women 30-34.9 years was 0.10 SD (95\% Confidence Interval (CI) 0.02 to 0.17 ), and for women aged $\geq 40$ years $0.33 \mathrm{SD}$ ( $95 \% \mathrm{CI} 0.08$ to 0.57 ), overall linear trend 0.02 SD (95\% CI 0.01 to 0.03 ) per year). Compared to women aged 25-29.9 years, women younger than 20 years had an increased risk of third trimester uterine artery notching (Odds Ratio (OR) 1.97 (95\% CI 1.30-3.00)). A linear trend was present with a decrease in risk of third trimester uterine artery notching per year increase in maternal age (OR 0.96 (95\% CI 0.94 to 0.98 )). Maternal age was not consistently associated with umbilical artery pulsatility indices or placental weight.

Conclusions: Young maternal age is associated with higher risk of third trimester uterine artery notching, whereas advanced maternal age is associated with a higher third trimester uterine artery resistance index, which may predispose to an increased risk of pregnancy complications.
\end{abstract}

(C) 2020 Elsevier B.V. All rights reserved.

\section{Introduction}

Young maternal age, defined as childbearing in women aged $<20$ years, and advanced maternal age, defined as childbearing in women aged $\geq 35$ years, are associated with adverse pregnancy outcomes, including fetal growth restriction, preterm birth, and fetal and neonatal death [1-5]. Mechanisms underlying these observed associations are not fully understood but are likely multifactorial, including pre-existing medical conditions, obstetrical history and social characteristics [5,6]. Next to these factors, both young or advanced maternal age might affect placental vascular development and function throughout pregnancy, predisposing to an increased risk of pregnancy complications [2]. A better

\footnotetext{
* Corresponding author at: The Generation R Study Group (Na 29-15), Erasmus MC, P.O. Box 2040, 3000 CA, Rotterdam, the Netherlands.

E-mail address: r.gaillard@erasmusmc.nl (R. Gaillard).
}

understanding of the role of maternal age in suboptimal placental development may aid screening for and early detection of symptoms associated with suboptimal placental development and the subsequent risk of pregnancy complications.

Placental function and growth can be assessed during pregnancy and at birth. Doppler ultrasound can be used to assess resistance and blood flow in uterine and umbilical arteries throughout pregnancy [7]. Utero-placental vascular resistance, measured in uterine arteries, is a parameter of downstream placental vascular resistance, and may increase as a result of impaired placentation. Feto-placental vascular resistance, measured in umbilical arteries, is a parameter of downstream placental vascular resistance at the fetal side, and may increase as result of suboptimal placentation or suboptimal fetal vascular development $[8,9]$.

We hypothesized that both young and advanced maternal age leads to suboptimal placental development and function, which may subsequently lead to alterations in utero-placental and fetoplacental blood flow and placental weight, predisposing to an 
increased risk of pregnancy complications. Therefore, in a population based, prospective cohort study among 8271 pregnant women, we assessed associations of maternal age across the full range with measures of placental vascular function throughout pregnancy and placental weight at birth.

\section{Methods}

\subsection{Study design}

This study was embedded in the Generation $R$ Study, a population-based prospective cohort study from early pregnancy onwards in Rotterdam, the Netherlands [10] (MEC 198.782/2001/ 31). Written consent was obtained from all participating women. Pregnant women were enrolled between 2001 and 2005. Response rate at birth was $61 \% .8879$ women were enrolled during pregnancy. We excluded non-singleton live births $(n=246)$, and participants with no information available on placental measurements $(n=362)$. The population for analysis comprised 8271 pregnant women (Figure 1).

\subsection{Maternal age}

Maternal age was assessed at enrolment by questionnaire. We used maternal age as continuous variable and categorized in six groups: $<20$ years $(n=338) ; 20-24.9$ years $(n=1391) ; 25-29.9$ years $(n=2256) ; \quad 30-34.9$ years $(n=3045) ; 35-39.9$ years $(n=1102)$; $>40$ years $(n=139)$ [11]. We used the $25-29.9$ years age group as reference.

\subsection{Placental vascular function and placental weight at birth}

Ultrasound examinations were carried out in two dedicated research centers in first trimester (median 13.2 weeks gestational age, interquartile range (IQR) 12.2-14.8), second trimester (median 20.5 weeks gestational age, IQR 19.9-21.3) and third trimester

Table 1

Characteristics of women $(n=8271)$.

\begin{tabular}{|c|c|c|c|c|c|c|}
\hline Characteristics & $\begin{array}{l}<20 \text { years } \\
n=338\end{array}$ & $\begin{array}{l}20-24.9 \text { years } \\
n=1391\end{array}$ & $\begin{array}{l}25-29.9 \text { years } \\
n=2256\end{array}$ & $\begin{array}{l}30-34.9 \text { years } \\
n=3045\end{array}$ & $\begin{array}{l}35-39.9 \text { years } \\
n=1102\end{array}$ & $\geq 40$ years $n=139$ \\
\hline \multicolumn{7}{|l|}{ Maternal characteristics } \\
\hline Age, years (median, IQR) & $19.0(18.2-19.5)$ & $22.8(21.6-24.0)$ & $27.8(26.4-28.9)$ & $32.4(31.2-33.6)$ & $36.6(35.7-37.9)$ & $41.2(40.5-42.3)$ \\
\hline Height, mean $(\mathrm{SD})(\mathrm{cm})$ & $165.1(6.4)$ & $165.3(7.1)$ & $166.4(7.4)$ & $168.3(7.3)$ & $168.2(7.5)$ & $167.9(8.2)$ \\
\hline Weight, mean (SD) (kg) & $65.3(13.4)$ & $67.8(13.8)$ & $69.7(14.2)$ & $69.6(12.5)$ & $71.0(12.1)$ & $72.3(13.6)$ \\
\hline $\begin{array}{l}\text { Body Mass Index, mean (SD) } \\
\left(\mathrm{kg} / \mathrm{m}^{2}\right)\end{array}$ & $23.9(4.6)$ & $24.8(4.7)$ & $25.1(4.9)$ & $24.6(4.3)$ & $25.1(4.1)$ & $25.6(4.6)$ \\
\hline Parity, No. nulliparous (\%) & $295(88.9)$ & 985 (71.9) & $1341(60.1)$ & $1538(51.0)$ & $370(33.9)$ & $49(36.0)$ \\
\hline $\begin{array}{l}\text { Education, No. higher } \\
\text { education (\%) }\end{array}$ & $2(0.7)$ & $101(8.2)$ & $718(35.1)$ & $1686(59.2)$ & $611(58.9)$ & $73(57.1)$ \\
\hline \multicolumn{7}{|l|}{ Race / Ethnicity, No. (\%) } \\
\hline Dutch or European, No. (\%) & $75(25.0)$ & $389(30.3)$ & 1107 (51.8) & 2105 (71.6) & $725(67.9)$ & $81(60.0)$ \\
\hline Surinamese, No. (\%) & $61(20.3)$ & $192(15.0)$ & $210(9.8)$ & $165(5.6)$ & $74(6.9)$ & $9(6.7)$ \\
\hline Turkish, No. (\%) & $32(10.6)$ & $236(18.4)$ & $253(11.8)$ & $155(5.3)$ & $49(4.6)$ & $6(4.4)$ \\
\hline Moroccan, No. (\%) & $19(6.3)$ & $157(12.2)$ & $192(9.0)$ & $118(4.0)$ & $50(4.7)$ & $12(8.9)$ \\
\hline $\begin{array}{l}\text { Cape Verdian or Dutch Antilles, } \\
\text { No. (\%) }\end{array}$ & $72(23.9)$ & $190(14.8)$ & $154(7.2)$ & $132(4.6)$ & $49(4.6)$ & $6(4.4)$ \\
\hline \multicolumn{7}{|l|}{ Smoking, No. (\%) } \\
\hline None, No. (\%) & $161(55.9)$ & $747(61.8)$ & $1454(73.8)$ & $2110(78.0)$ & $717(73.8)$ & $89(77.4)$ \\
\hline Early-pregnancy only, No. (\%) & $27(9.4)$ & $102(8.4)$ & $172(8.7)$ & $238(8.8)$ & $74(7.4)$ & $7(6.1)$ \\
\hline Continued, No. (\%) & $100(34.7)$ & $360(29.8)$ & $343(17.4)$ & $358(13.2)$ & $181(18.6)$ & $19(16.5)$ \\
\hline Folic acid use No. used (\%) & $71(30.5)$ & $809(83.4)$ & $1156(70.0)$ & $1942(82.1)$ & $637(76.7)$ & $73(71.6)$ \\
\hline $\begin{array}{l}2^{\text {nd }} \text { trimester uterine artery RI, } \\
\text { mean }(\mathrm{SD})\end{array}$ & $0.56(0.09)$ & $0.54(0.09)$ & $0.54(0.09)$ & $0.54(0.09)$ & $0.55(0.09)$ & $0.56(0.09)$ \\
\hline $\begin{array}{l}2^{\text {nd }} \text { trimester umbilical artery } \\
\text { PI, mean (SD) }\end{array}$ & $1.24(0.19)$ & $1.23(0.19)$ & $1.21(0.18)$ & $1.19(0.18)$ & $1.18(0.19)$ & $1.17(0.19)$ \\
\hline $\begin{array}{l}3^{\text {rd }} \text { trimester uterine artery RI, } \\
\text { mean }(S D)\end{array}$ & $0.48(0.08)$ & $0.48(0.07)$ & $0.48(0.08)$ & $0.48(0.08)$ & $0.50(0.08)$ & $0.51(0.07)$ \\
\hline $\begin{array}{l}3^{\text {rd }} \text { trimester umbilical artery } \\
\text { PI, mean (SD) }\end{array}$ & $0.99(0.16)$ & $0.99(0.17)$ & $0.99(0.17)$ & $0.98(0.17)$ & $0.98(0.17)$ & $0.97(0.19)$ \\
\hline $\begin{array}{l}\text { 3rd trimester uterine artery } \\
\text { notching, No. }(\%)\end{array}$ & $40(22.5)$ & $113(14.8)$ & $137(10.8)$ & $146(7.9)$ & $50(7.6)$ & $6(8.1)$ \\
\hline \multicolumn{7}{|l|}{ Birth characteristics } \\
\hline Males, No.(\%) & $164(48.5)$ & $713(51.3)$ & $1131(50.1)$ & $1536(50.4)$ & $572(51.9)$ & $72(51.8)$ \\
\hline $\begin{array}{l}\text { Gestational age at delivery, } \\
\text { weeks (IQR) }\end{array}$ & $39.9(38.7-40.8)$ & $40.0(39.1-40.9)$ & $40.1(39.0-41.0)$ & $40.1(39.4-41.0)$ & $40.3(39.3-41.0)$ & $40.3(38.7-41.1)$ \\
\hline Birth weight, mean (SD) grams & $3184(516)$ & $3315(522)$ & $3399(551)$ & $3461(576) 4$ & 3487 (549) & $3424(656)$ \\
\hline $\begin{array}{l}\text { Small-size for gestational age, } \\
\text { No. (\%) }\end{array}$ & $53(15.7)$ & $191(13.7)$ & $214(9.5)$ & $254(8.3)$ & $97(8.8)$ & $13(9.4)$ \\
\hline $\begin{array}{l}\text { Large-size for gestational age, } \\
\text { No. }(\%)\end{array}$ & $16(4.7)$ & $75(5.4)$ & $209(9.3)$ & $379(12.4)$ & $122(11.1)$ & $20(14.4)$ \\
\hline Preterm birth & $27(8.0)$ & $65(4.7)$ & $128(5.7)$ & $153(5.0)$ & $50(4.5)$ & $9(6.5)$ \\
\hline Assisted vaginal delivery & $29(9.8)$ & $156(12.4)$ & $301(14.6)$ & $409(14.7)$ & $128(12.7)$ & $10(7.7)$ \\
\hline Cesarean delivery & $28(9.5)$ & $111(8.8)$ & $249(12.1)$ & $363(13.0)$ & $142(14.0)$ & $32(24.6)$ \\
\hline Gestational hypertension & $13(4.1)$ & $42(3.2)$ & $80(3.8)$ & $117(4.1)$ & $41(3.9)$ & $4(3.1)$ \\
\hline Preeclampsia & $10(3.2)$ & $23(1.8)$ & $58(2.8)$ & $57(2.0)$ & $15(1.5)$ & $3(2.3)$ \\
\hline APGAR $<7$ after $5 \mathrm{~min}$, No. (\%) & $5(1.6)$ & $18(1.3)$ & $27(1.2)$ & $38(1.3)$ & $11(1.0)$ & $1(0.7)$ \\
\hline $\begin{array}{l}\text { Placental weight (grams) } \\
\text { median (IQR) }\end{array}$ & $600(500-695)$ & $600(520-700)$ & $620(540-713)$ & $630(545-725)$ & $619(530-724)$ & $650(530-732)$ \\
\hline
\end{tabular}

Abbreviation: IQRinter quartile range. Values are observed data and represent means (SD), medians (IQR) or number of subjects (valid\%). 
(median 30.3 weeks gestational age, IQR 29.8-30.9)[12]. We established gestational age by using data from the first ultrasound examination [13]. In second and third trimester, uterine artery resistance indices were measured in the uterine arteries near the crossover with the external iliac artery and umbilical artery pulsatility indices were measured in a free-floating loop of the umbilical cord as described previously [8]. The mean of three measurements was used for further analysis. Third trimester uterine artery notching was diagnosed if a notch was present unior bilaterally, as a result from increased blood flow resistance, which is a sign of placental insufficiency [14]. Placental weight was obtained from medical records and measured according to standard protocols [15]. Birth weight:placental weight ratio was calculated, as indicator of the ability of the placenta to maintain adequate nutrient supply to the fetus, and is associated with neonatal morbidity and mortality [16]. Small-size for gestational age (SGA) was defined as gestational age adjusted birth weight $<10$ th percentile. Large-size for gestational age (LGA) is defined as gestational age adjusted birth weight $>90$ th percentile.

\subsection{Covariates}

Maternal height $(\mathrm{cm})$ and weight $(\mathrm{kg})$ were measured without shoes and heavy clothing at enrolment. Body mass index (BMI, kg/ $\mathrm{m}^{2}$ ) was calculated and categorized: normal weight (BMI $<25 \mathrm{~kg} /$ $\mathrm{m}^{2}$ ), overweight (BMI $25.0-30.0 \mathrm{~kg} / \mathrm{m}^{2}$ ) and obese (BMI $\geq 30.0 \mathrm{~kg} /$ $\mathrm{m}^{2}$ ) [17]. Information about ethnicity (European/non-European), education (higher education yes/no), folic acid supplementation (yes/no) and parity (nulliparous/multiparous), was obtained at enrolment by questionnaire [18]. Smoking status was assessed by questionnaires and categorized into non-smoking, early-pregnancy only and continued smoking during pregnancy [13].

\subsection{Statistical analyses}

First, we used linear and logistic regression models to assess the associations of maternal age categories with second and third trimester uterine artery resistance indices and umbilical artery pulsatility indices, uterine artery notching, placental weight, birth weight and birth weight:placental weight ratio. P-values for trend were obtained by entering maternal age to the models as a continuous instead of a categorical variable. These models were adjusted for gestational age at each measurement, maternal education, ethnicity, parity, smoking, BMI, folic acid supplementation and fetal sex. These covariates were selected based on previous studies and their associations with the outcomes [11,19,20].As a secondary analysis, we took forward significant associations of maternal age with placental vascular resistance and explored whether changes in placental vascular resistance partly explained the already established association of maternal age with birth weight [20]. We therefore additionally added placental vascular resistance parameters to linear regression models focused on the associations of maternal age with birth weight, and to logistic regression models focused on the associations of maternal age with risk of delivering an SGA newborn. We used multiple imputation for missing values according to Markov Chain Monte Carlo method [21]. Five imputed datasets were created and pooled for the analyses. Analyses were performed using the Statistical Package of Social Sciences version 24.0 for Windows (IBM Corp., Armonk, NY, USA).

\section{Results}

\subsection{Population characteristics}

Table 1 shows population characteristics according to maternal age categories. Younger women were more likely to be of nonDutch or European ethnicity, to smoke, to have a lower BMI, and to deliver an SGA newborn. Older women were more likely to be of Dutch or European ethnicity and parous, and to deliver an LGA newborn.

\subsection{Maternal age and placental vascular function}

Maternal age was not associated with second trimester uterine artery resistance index (Table 2). Compared to women aged 25-29.9 years, higher maternal age was associated with a higher

Table 2

Associations of maternal age with uterine artery resistance indices and notching

\begin{tabular}{|c|c|c|c|}
\hline & \multicolumn{2}{|c|}{ Difference in uterine artery resistance index ${ }^{a}$} & \multirow{3}{*}{$\begin{array}{l}\text { Uterine artery notching }{ }^{\mathrm{b}} \\
\text { Third trimester } n=4762 \\
\text { Odds ratio }(95 \% \mathrm{CI})\end{array}$} \\
\hline & Second trimester $n=4578$ & Third trimester $n=4479$ & \\
\hline & SDS difference (95\% CI) & SDS difference (95\% CI) & \\
\hline \multicolumn{4}{|l|}{ Maternal age } \\
\hline \multirow[t]{2}{*}{$<20$ years } & $0.12(-0.05$ to 0.29$)$ & $-0.02(-0.19$ to 0.15$)$ & $1.97(1.30-3.00)^{*}$ \\
\hline & $n=159$ & $n=169$ & $n=178$ \\
\hline \multirow{2}{*}{$20-24.9$ years } & $-0.02(-0.05$ to 0.08$)$ & $-0.00(-0.10$ to 0.09$)$ & $1.25(0.994-1.66)$ \\
\hline & $n=715$ & $n=717$ & $\mathrm{n}=755$ \\
\hline \multirow[t]{2}{*}{$25-29.9$ years } & reference & Reference & Reference \\
\hline & $n=1268$ & $n=1179$ & $n=1272$ \\
\hline \multirow[t]{2}{*}{ 30-34.9 years } & $-0.00(-0.08$ to 0.07$)$ & $0.10(0.02 \text { to } 0.17)^{*}$ & $0.79(0.61-1.03)$ \\
\hline & $n=1760$ & $n=1745$ & $n=1826$ \\
\hline \multirow[t]{2}{*}{$35-39.9$ years } & $0.04(-0.07$ to 0.14$)$ & $0.18(0.08 \text { to } 0.29)^{*}$ & $0.77(0.54-1.11)$ \\
\hline & $n=611$ & $n=601$ & $n=657$ \\
\hline \multirow[t]{2}{*}{$\geq 40$ years } & $0.18(-0.07$ to 0.44$)$ & $0.33(0.08 \text { to } 0.57)^{*}$ & $0.85(0.36-2.01)$ \\
\hline & $n=65$ & $n=68$ & $n=74$ \\
\hline Trend $^{\mathrm{c}}$ & $0.00(-0.00$ to 0.01$)$ & $0.02(0.01 \text { to } 0.03)^{*}$ & $0.96(0.94 \text { to } 0.98)^{*}$ \\
\hline
\end{tabular}

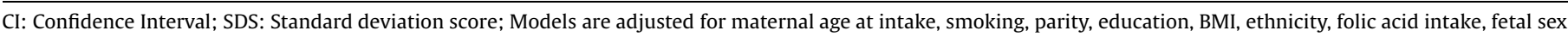
and gestational age at ultrasound measurement.

*Significant value $(p<0.05)$.

a Values are regression coefficients (95\% confidence interval) that reflect the difference in SDS score or odds ratio per measurement per maternal age-group compared to

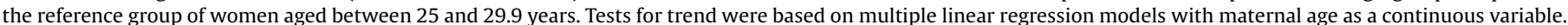
The trends are differences in measurements per additional maternal year.

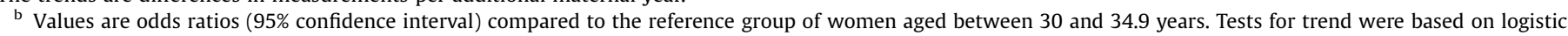
regression models with maternal age as a continuous variable.

c Tests for trend were based on multiple linear and logistic regression models with maternal age as a continuous variable. The trends are differences in regression coefficients and odds ratio per additional maternal year. 
Table 3

Associations of maternal age with umbilical artery pulsatility indices.

\begin{tabular}{lll}
\hline & \multicolumn{2}{l}{ Difference in umbilical artery pulsatility index } \\
\hline & $\begin{array}{l}\text { Second trimester } n=6141 \\
\text { SDS difference }(95 \% \mathrm{CI})\end{array}$ & $\begin{array}{l}\text { Third trimester } n=6668 \\
\text { SDS difference }(95 \% \mathrm{CI})\end{array}$ \\
Maternal age & & \\
$<20$ years & $0.04(-0.10$ to 0.18$)$ & $-0.08(-0.21$ to 0.06$)$ \\
& $n=228$ & $n=259$ \\
$20-24.9$ years & $0.06(-0.02$ to 0.14$)$ & $-0.01(-0.09$ to 0.07$)$ \\
& $n=978$ & $n=1104$ \\
25-29.9 years & reference & reference \\
& $n=1693$ & $n=1804$ \\
$30-34.9$ years & $-0.00(-0.07$ to 0.06$)$ & $-0.03(-0.09$ to 0.07$)$ \\
& $n=2333$ & $n=2502$ \\
$35-39.9$ years & $-0.01(-0.09$ to 0.08$)$ & $0.02(-0.07$ to 0.10$)$ \\
& $n=821$ & $n=888$ \\
$\geq 40$ years & $-0.03(-0.24$ to 0.18$)$ & $0.02(-0.17$ to 0.21$)$ \\
& $n=88$ & $n=111$ \\
Trend & $-\mathbf{0 . 0 0}(-\mathbf{0 . 0 1}$ to $\mathbf{0 . 0 0})$ & $\mathbf{0 . 0 0}(-\mathbf{0 . 0 0}$ to $\mathbf{0 . 0 1})$ \\
\hline
\end{tabular}

CI: Confidence Interval; SDS: Standard deviation score;

Models are adjusted for maternal age at intake, smoking, parity, education, BMI, ethnicity, folic acid intake, fetal sex and gestational age at ultrasound measurement. Values are regression coefficients (95\% confidence interval) that reflect the difference in SDS per measurement per maternal age-group compared to the reference group of women aged between 25 and 29.9 years. Tests for trend were based on multiple linear regression models with maternal age as a continuous variable. The trends are differences in SDS per additional maternal year.

third trimester uterine artery resistance index (difference for women 30-34.9 years was 0.10 SD (95\% Confidence Interval (CI) $0.02 ; 0.17)$, and for women aged $\geq 40$ years 0.33 SD $(95 \% \mathrm{CI}$ $0.08 ; 0.57)$, overall linear trend $0.02 \operatorname{SDS}(95 \% \mathrm{CI} 0.01 ; 0.03)$ per year). As compared to women aged 25-29.9 years, women younger than 20 years had an increased risk of third trimester uterine artery notching (Odds Ratio 1.97 (95\%CI 1.30;3.00)). A linear trend was present with a decrease in risk of third trimester uterine artery notching per year increase in maternal age (OR 0.96 (95\%CI 0.94;0.98)).We did not observe associations of maternal age with second or third trimester umbilical artery pulsatility index (Table 3).

3.3 Maternal age and placental weight, birth weight and birth weight: placental weight ratio

Compared to women aged 25-29.9 years, women aged 35-39.9 years had a lower placental weight $(-12 \mathrm{~g}$ (95\% CI
$-24.0 ;-0.17)$ and gave birth to newborns with a lower birth weight $(-34 \mathrm{~g}(95 \% \mathrm{CI}-66 ;-1.3))$, and a higher birth weight: placental weight ratio (ratio difference 0.12 (95\% CI $0.03 ; 0.22)$ ) (Table 4). Women aged $\geq 40$ gave birth to newborns with a lower birth weight ( $p$-value $<0.05$ ), but no difference in placental weight was present. A decreasing trend for birth weight was present across the full range of maternal age $(-2.5 \mathrm{~g}$ per additional year $(95 \% \mathrm{CI}-4.7 ; 0.3))$, but not for placental weight. As higher maternal age was significantly associated with higher third trimester uterine artery vascular resistance and lower birth weight, we explored whether third trimester uterine artery vascular resistance partly explained this observed association of higher maternal age with a lower birth weight and the risk of delivering an SGA newborn. Table S1 and S2 show that additional adjustment for third trimester uterine artery vascular resistance partly attenuated the association of maternal age with birth weight, and the risk of delivering an SGA newborn.

\section{Discussion}

\subsection{Principal findings}

We observed that after adjustment for socio-demographic and lifestyle factors, young maternal age was associated with an increased risk of third trimester uterine artery notching, whereas advanced maternal age was associated with an increased third trimester uterine artery resistance index. Maternal age was not associated with second trimester uterine artery resistance index or second and third trimester umbilical artery pulsatility indices. Advanced maternal age tended to be associated with lower placental and birth weight and higher birth weight:placental weight ratio, but this association was not consistent across the full range of maternal age.

\subsection{Results}

Both young and advanced maternal age are associated with an increased risk of pregnancy complications [2]. Suboptimal placental function may play a key role in the pathophysiology of these placenta-related complications, but studies focusing on pathophysiological mechanisms are scarce [22,23]. Obtaining a better insight into potential placenta-related pathophysiological mechanisms underlying the observed associations of young and

Table 4

Associations of maternal age with placental weight, birth weight and birth weight:placental weight ratio.

\begin{tabular}{|c|c|c|c|}
\hline & Placental weight at birth & Birth weight & Birth weight:Placental weight ratio \\
\hline & $n=6197$ & $n=8224$ & $n=6197$ \\
\hline & Difference in grams $(95 \% \mathrm{CI})$ & Difference in grams $(95 \% \mathrm{CI})$ & Difference in ratio $(95 \% \mathrm{CI})$ \\
\hline \multicolumn{4}{|l|}{ Maternal age } \\
\hline \multirow[t]{2}{*}{$<20$ years } & $-6(-25$ to 13$)$ & $-23(-74$ to 29$)$ & $0.04(-0.10$ to 0.19$)$ \\
\hline & $n=249$ & $n=332$ & $n=249$ \\
\hline \multirow[t]{2}{*}{$20-24.9$ years } & $-1(-12$ to 10$)$ & $0(-30$ to 30$)$ & $0.00(-0.08$ to 0.09$)$ \\
\hline & $n=1064$ & $n=1381$ & $n=1064$ \\
\hline \multirow[t]{2}{*}{$25-29.9$ years } & reference & Reference & reference \\
\hline & $n=1707$ & $n=2247$ & $n=1707$ \\
\hline \multirow[t]{2}{*}{$30-34.9$ years } & -0.0 ( -9 to 9$)$ & $-1(-25$ to 23$)$ & $0.00(-0.07$ to 0.07$)$ \\
\hline & $n=2230$ & $n=3029$ & $n=2230$ \\
\hline \multirow[t]{2}{*}{ 35-39.9 years } & $-12(-24 \text { to }-0)^{*}$ & $-34(-66 \text { to }-1.3)^{*}$ & $0.12(0.03 \text { to } 0.22)^{*}$ \\
\hline & $n=833$ & $n=1096$ & $n=833$ \\
\hline \multirow{2}{*}{$\geq 40$ years } & $-9(-35$ to 18$)$ & $-80(-155 \text { to }-6)^{*}$ & $0.01(-0.20$ to 0.22$)$ \\
\hline & $n=114$ & $n=139$ & $n=114$ \\
\hline Trend & $-0(-1$ to 0$)$ & $-2.5(-4.7 \text { to }-0.3)^{*}$ & $0.00(-0.00$ to 0.01$)$ \\
\hline
\end{tabular}

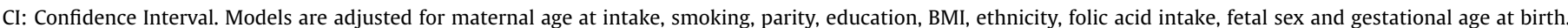

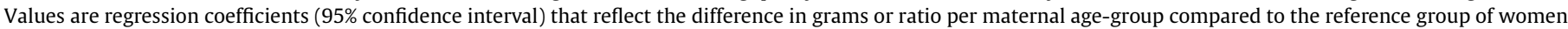

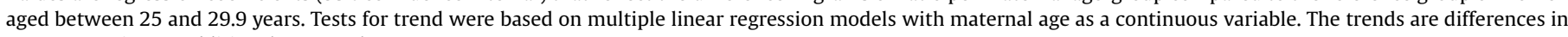
grams or ratio per additional maternal year.

*Significant value $(p<0.05)$. 
advanced maternal age with pregnancy complications is important to develop future prevention, screening and treatment strategies for a population that is increasingly of advanced maternal age during pregnancy.

For young maternal age, previous studies have only focused on the associations of young maternal age with placental weight and showed conflicting findings [24,25]. In a study among 31 adolescent pregnancies, young maternal age had no effect on placental weight, morphometry or cell turnover [25]. A study among 552 mothers and their healthy singleton newborns, found no association of young maternal age with placental weight [26]. However, a study among 431 uncomplicated singleton near-term deliveries, showed that young maternal age was associated with a low birth weight:placental weight ratio [27].We observed that the risk of third trimester uterine artery notching was increased among women aged $<20$ years, but we did not observe associations with uterine artery resistance or umbilical artery pulsatility indices across the full range. There were no associations of young maternal age with placental weight or placental weight:birth weight ratio. Thus, our findings seem to suggest that young maternal age may specifically be associated with a suboptimal third trimester utero-placental vascular function. Normally, in early pregnancy, trophoblast invasion and spiral artery remodeling takes place to ensure adequate blood flow to the placenta, leading to larger vessels with lower resistance and increased end diastolic flow [28]. If these processes are inadequate, abnormal uterine artery flow patterns with higher resistance indices and notching may be observed, which is strongly associated with the risk of pregnancy complications. This may be the case in biologic immaturity among adolescent pregnancies [29]. It might be that young maternal age mostly affects placentation leading to an increased risk of notching, but due to overall adequate vascular quality and dynamics of young women, small changes in utero-placental flow and resistance can be more easily compensated. The lack of associations with other placental vascular function markers and placental weight might be due to the relatively high ( 19 years) young maternal age in our study.

The effects of advanced maternal age on placental function have been studied in larger populations. A study among 536,954 singleton births showed that older women had larger placentas [30]. It was suggested that this enlargement represents a biological compensatory mechanism for suboptimal placental function, to secure a threatened pregnancy [30]. Possibly, other maternal characteristics which influence placental weight and are strongly related to maternal age, such as parity, may be responsible for the larger placentas among older women [30]. A observational prospective study among 24,152 singleton livebirths, found that after correction for maternal characteristics, such as parity, BMI, cigarette use, socio-economic status and race, higher maternal age was associated with lower placental weight [31]. A cross-sectional study among 884 pregnant women showed that after adjustment for gestational age and parity, advanced maternal age was associated with an increased uterine artery pulsatility index in the second half of pregnancy [32]. We observed that after correction for socio-demographic and lifestyle factors, higher maternal age was associated with an increased third trimester uterine artery resistance index, and that the effect of maternal age on uterine artery vascular resistance is already visible from 30 years onwards. These effects of advanced maternal age on third trimester uterine artery vascular resistance were small and within the normal range. However, several studies have shown that small increases in utero-placental vascular resistance, even within the normal range, is associated with pregnancy complications [33-36]. Importantly, the direction of the normal changes in hemodynamics during pregnancy seems to be opposite to the changes that occur in ageing [37]. Previous studies have shown that with ageing, uterine blood flow diminishes, uterine blood vessels are less compliant, and endothelium-dependent function is altered [32,37,38]. The increased uterine artery vascular resistance may indeed be explained by general reduced vascular compliance among older women, whereas newly constructed fetal vasculature is not affected by the effects of advanced maternal age on vascular quality, which could explain lack of effect on feto-placental vascular function in our study. As differences in third trimester uterine artery vascular resistance were within the normal range and we observed no associations with the risk of third trimester notching, our findings may suggest that not suboptimal placentation explains these observed associations, but rather overall reduced vascular quality due to advanced maternal age. We further observed that higher maternal age was associated with a lower birth weight, and an increased risk of delivering an SGA newborn, and that this association attenuated after considering third trimester uterine artery vascular resistance. This suggests that even this small difference in third trimester utero-placental vascular function among older women may play a pathophysiological role in the established associations of advanced maternal age with an increased risk of pregnancy complications, such as an abnormal birth weight.

Our findings provide insight into potential pathophysiological mechanisms explaining observed associations of young and advanced maternal age with pregnancy complications. From a clinical perspective, measurement of utero-placental vascular function among pregnant women with a young or advanced maternal age could possibly aid in screening for those pregnancies at risk of adverse pregnancy outcomes. However, the additional value of using utero-placental vascular function for screening for adverse pregnancy outcomes may depend upon specific populations and pregnancy outcomes of interest. We have previously shown within the same study population that among low-risk, multi ethnic women combined second and third trimester utero-placental vascular function ultrasound results in addition to maternal characteristics improved screening for preeclampsia but not for gestational hypertension [39]. A systematic review has shown that model performance for screening for gestational hypertensive disorders varies with the use of different maternal, fetal and placental characteristics among low-risk and high-risk populations [40]. A meta-analysis comprising seventeen observational studies showed that among SGA fetuses and newborns, which is considered a high-risk population, concluded that an increased UtA-PI increased the risk of adverse perinatal outcomes, but because of limited predictive capacity as a standalone test, UtA-PI should be combined in combination with other tests [41]. Although causality cannot be established in observational research, these findings suggest that maternal age may, through suboptimal utero-placental vascular function, influence pregnancy outcomes. Among young maternal age pregnancies, impaired placental development may be due to biologic immaturity, whereas among advanced maternal age pregnancies, reduced vascular quality due to ageing may play a key role. Further mechanistic studies are needed to obtain a better understanding of these potential pathways, by using more advanced placental imaging techniques from early pregnancy onwards, placental biomarkers or detailed assessments of placental vasculature at birth through placental biopsy. Large meta-analyses on patient level data are necessary to enable assessment of associations at the extremes of the maternal age spectrum where numbers are smaller and to enable identification of the optimal maternal age at pregnancy for various pregnancy outcomes. 


\subsection{Strengths and limitations}

Bias due to nonresponse at baseline is unlikely because biased estimates in large cohort studies mainly arise from loss to follow-up rather than from nonresponse at baseline [42]. Selection of a healthy population might affect the generalizability of results to higher-risk populations. As clinical practice guidelines during the inclusion period of the current study (2001-2006) did not recommend Aspirin prophylaxis, we do not have information on Aspirin use available. Although we do not think that the use Aspirin prophylaxis, or rather the lack thereof, has biased the results of the current study, it may limit the generalizability of our results to contemporary populations. Finally, we had a relatively small number of women in the age group 40 years and older and these results should be interpreted with caution. Although we adjusted for a number of potential confounders, residual confounding by other lifestyle factors might still be present.

\section{Conclusions}

Young maternal age is associated with higher risk of third trimester uterine artery notching, whereas advanced maternal age is associated with higher third trimester uterine artery resistance index, which may predispose to an increased risk of pregnancy complications. These associations are not explained by maternal socio-demographic or lifestyle characteristics.

\section{Ethical Standards}

The authors assert that all procedures contributing to this work comply with the ethical standards of the relevant national guidelines on human experimentation and with the Helsinki Declaration of 1975 , as revised in 2008, and has been approved by the institutional committees (MEC 198.782/2001/31)).

\section{Authors Roles}

JE and RG had full access to all of the data in the study and take responsibility for the integrity of the data and the accuracy of the data analysis. The corresponding author attests that all listed authors meet authorship criteria and that no others meeting the criteria have been omitted.

\section{Study concept and design}

JE, VJ, RGAnalysis and interpretation of data: JE,VJ, RGDrafting of the manuscript: JE, VJ, RGCritical revision of the manuscript for important intellectual content: All authors

\section{Financial support}

The Generation R Study was supported by financial support by the Erasmus Medical Center, Rotterdam, the Erasmus University Rotterdam, the Netherlands Organization for Health Research and Development (ZonMw), the Netherlands Organisation for Scientific Research (NWO), the Ministry of Health, Welfare and Sport and the Ministry of Youth and Families. Vincent Jaddoe received grants from the Netherlands Organization for Health Research and Development (VIDI 016.136.361) and the European Research Council (Consolidator Grant, ERC2014-CoG-648916). Romy Gaillard received funding from the Dutch Heart Foundation (grant number 2017T013), the Dutch Diabetes Foundation (grant number 2017.81.002) and ZonMw (grant number 543003109).

\section{Funding}

ZonMw (VIDI 016.136.361), European Research Council (Consolidator Grant, ERC-2014-CoG-648916). Dutch Heart Foundation (grant number 2017T013). Dutch Diabetes Foundation (grant number 2017.81.002). ZonMw (grant number 543003109).

\section{Declaration of Competing Interest}

None.

\section{Acknowledgements}

The Generation R Study is conducted by the Erasmus Medical Center in close collaboration with the School of Law and Faculty of Social Sciences of the Erasmus University Rotterdam, the Municipal Health Service Rotterdam area, Rotterdam, the Rotterdam Homecare Foundation, Rotterdam, and the Stichting Trombosedienst and Artsenlaboratorium Rijnmond (STAR). We gratefully acknowledge the contribution of participating women, general practitioners, hospitals, midwives and pharmacies in Rotterdam.

\section{References}

[1] Paulson RJ, Boostanfar R, Saadat P, Mor E, Tourgeman DE, Slater CC, et al. Pregnancy in the sixth decade of life: obstetric outcomes in women of advanced reproductive age. JAMA 2002;288:2320-3.

[2] Lean SC, Derricott H, Jones RL, Heazell AEP. Advanced maternal age and adverse pregnancy outcomes: a systematic review and meta-analysis. PLoS ONE 2017;12:e0186287.

[3] Cleary-Goldman J, Malone FD, Vidaver J, Ball RH, Nyberg DA, Comstock CH, et al. Impact of maternal age on obstetric outcome. Obstet Gynecol 2005; 105:983-90.

[4] Kenny LC, Lavender T, McNamee R, O’Neill SM, Mills T, Khashan AS. Advanced maternal age and adverse pregnancy outcome: evidence from a large contemporary cohort. PLoS ONE 2013;8:e56583.

[5] Ganchimeg T, Mori R, Ota E, Koyanagi A, Gilmour S, Shibuya K, et al. Maternal and perinatal outcomes among nulliparous adolescents in low- and middleincome countries: a multi-country study. BJOG 2013;120:1622-30 discussion 30 .

[6] Goisis A, Remes H, Barclay K, Martikainen P, Myrskyla M. Advanced maternal age and the risk of low birth weight and preterm delivery: a within-family analysis using finnish population registers. Am J Epidemiol 2017;186:1219-26.

[7] Kennedy AM, Woodward PJ. A radiologist's guide to the performance and interpretation of obstetric doppler US. Radiographics 2019;39:893-910.

[8] Gaillard R, Steegers EA, Tiemeier H, Hofman A, Jaddoe VW. Placental vascular dysfunction, fetal and childhood growth, and cardiovascular development: the generation R study. Circulation 2013;128:2202-10.

[9] Kampman MA, Bilardo CM, Mulder BJ, Aarnoudse JG, Ris-Stalpers C, van Veldhuisen DJ, et al. Maternal cardiac function, uteroplacental Doppler flow parameters and pregnancy outcome: a systematic review. Ultrasound Obstet Gynecol 2015;46:21-8.

[10] Jaddoe VW, van Duijn CM, Franco OH, van der Heijden AJ, van Iizendoorn MH, de Jongste JC, et al. The generation r study: design and cohort update2012. Eur J Epidemiol 2012;(27):739-56.

[11] Gaillard R, Bakker R, Steegers EA, Hofman A, Jaddoe VW. Maternal age during pregnancy is associated with third trimester blood pressure level: the generation R study. Am J Hypertens 2011;24:1046-53.

[12] Verburg BO, Steegers EA, De Ridder M, Snijders RJ, Smith E, Hofman A, et al New charts for ultrasound dating of pregnancy and assessment of fetal growth: longitudinal data from a population-based cohort study. Ultrasound Obstet Gynecol 2008;31:388-96.

[13] Gaillard R, Steegers EA, de Jongste JC, Hofman A, Jaddoe VW. Tracking of fetal growth characteristics during different trimesters and the risks of adverse birth outcomes. Int J Epidemiol 2014;43:1140-53.

[14] Li H, Gudnason H, Olofsson P, Dubiel M, Gudmundsson S. Increased uterine artery vascular impedance is related to adverse outcome of pregnancy but is present in only one-third of late third-trimester pre-eclamptic women. Ultrasound Obstet Gynecol 2005;25:459-63.

[15] Rurangirwa AA, Gaillard R, Steegers EA, Hofman A, Jaddoe VW. Hemodynamic adaptations in different trimesters among nulliparous and multiparous pregnant women; the Generation R study. Am J Hypertens 2012;25:892-9.

[16] Salavati N, Gordijn SJ, Sovio U, Zill EHR, Gebril A, Charnock-Jones DS, et al. Birth weight to placenta weight ratio and its relationship to ultrasonic measurements, maternal and neonatal morbidity: a prospective cohort study of nulliparous women. Placenta 2018;63:45-52.

[17] Gaillard R, Durmus B, Hofman A, Mackenbach JP, Steegers EA, Jaddoe VW. Risk factors and outcomes of maternal obesity and excessive weight gain during pregnancy. Obesity (Silver Spring) 2013;21:1046-55. 
[18] Gaillard R, Rurangirwa AA, Williams MA, Hofman A, Mackenbach JP, Franco $\mathrm{OH}$, et al. Maternal parity, fetal and childhood growth, and cardiometabolic risk factors. Hypertension 2014;64:266-74.

[19] Barjaktarovic M, Korevaar TI, Chaker L, Jaddoe VW, de Rijke YB, Visser TJ, et al. The association of maternal thyroid function with placental hemodynamics. Hum Reprod 2017;32:653-61.

[20] Bakker R, Steegers EA, Biharie AA, Mackenbach JP, Hofman A, Jaddoe VW. Explaining differences in birth outcomes in relation to maternal age: the Generation R Study. BJOG 2011;118:500-9.

[21] Sterne JA, White IR, Carlin JB, Spratt M, Royston P, Kenward MG, et al. Multiple imputation for missing data in epidemiological and clinical research: potential and pitfalls. BMJ 2009;338:b2393.

[22] Hayward CE, Greenwood SL, Sibley CP, Baker PN, Challis JR, Jones RL. Effect of maternal age and growth on placental nutrient transport: potential mechanisms for teenagers' predisposition to small-for-gestational-age birth? Am Physiol Endocrinol Metab 2012;302:E233-42.

[23] Lean SC, Heazell AEP, Dilworth MR, Mills TA, Jones RL. Placental dysfunction underlies increased risk of fetal growth restriction and stillbirth in advanced maternal age women. Sci Rep 2017;7:9677.

[24] Wallace JM, Bourke DA, Aitken RP, Leitch N, Hay [172_TD\$DIFF][158_TD\$DIFF] Jr. WW. Blood flows and nutrient uptakes in growth-restricted pregnancies induced by overnourishing adolescent sheep. Am J Physiol Regul Integr Comp Physiol 2002;282:R1027-36.

[25] Hayward CE, Greenwood SL, Sibley CP, Baker PN, Jones RL. Effect of young maternal age and skeletal growth on placental growth and development. Placenta 2011;32:990-8.

[26] Lo YF, Jeng MJ, Lee YS, Soong WJ, Hwang B. Placental weight and birth characteristics of healthy singleton newborns. Acta Paediatr Taiwan 2002:43:21-5.

[27] Lurie S, Feinstein M, Mamet Y. Human fetal-placental weight ratio in normal singleton near-term pregnancies. Gynecol Obstet Invest 1999;48:155-7.

[28] Lin S, Shimizu I, Suehara N, Nakayama M, Aono T. Uterine artery Doppler velocimetry in relation to trophoblast migration into the myometrium of the placental bed. Obstet Gynecol 1995;85:760-5.

[29] Park YW, Cho JS, Choi HM, Kim TY, Lee SH, Yu JK, et al. Clinical significance of early diastolic notch depth: uterine artery Doppler velocimetry in the third trimester. Am J Obstet Gynecol 2000;182:1204-9.

[30] Haavaldsen C, Samuelsen SO, Eskild A. The association of maternal age with placental weight: a population-based study of 536,954 pregnancies. BJOC 2011;118:1470-6.
[31] Salafia CM, Zhang J, Charles AK, Bresnahan M, Shrout P, Sun W, et al. Placental characteristics and birthweight. Paediatr Perinat Epidemiol 2008;22:229-39.

[32] Pirhonen J, Bergersen TK, Abdlenoor M, Dubiel M, Gudmundsson S. Effect of maternal age on uterine flow impedance. J Clin Ultrasound 2005:33:14-7.

[33] Cooley SM, Donnelly JC, Walsh T, MacMahon C, Gillan J, Geary MP. The impact of umbilical and uterine artery Doppler indices on antenatal course, labor and delivery in a low-risk primigravid population. J Perinat Med 2011:39:143-9.

[34] Coleman MA, McCowan LM, North RA. Mid-trimester uterine artery Doppler screening as a predictor of adverse pregnancy outcome in high-risk women. Ultrasound Obstet Gynecol 2000;15:7-12.

[35] Groom KM, North RA, Stone PR, Chan EH, Taylor RS, Dekker GA, et al. Patterns of change in uterine artery Doppler studies between 20 and 24 weeks of gestation and pregnancy outcomes. Obstet Gynecol 2009;113:332-8.

[36] Gaillard R, Arends LR, Steegers EA, Hofman A, Jaddoe VW. Second- and thirdtrimester placental hemodynamics and the risks of pregnancy complications: the Generation R Study. Am J Epidemiol 2013;177:743-54.

[37] Usta IM, Nassar AH. Advanced maternal age. Part I: Obstetric complications. Am J Perinatol. 2008;25:521-34.

[38] Care AS, Bourque SL, Morton JS, Hjartarson EP, Davidge ST. Effect of advanced maternal age on pregnancy outcomes and vascular function in the rat. Hypertension 2015;65:1324-30.

[39] Erkamp JS, Jaddoe WV, Duijts L, Reiss IKM, Mulders A, Steegers EAP, et al. Population screening for gestational hypertensive disorders using maternal, fetal and placental characteristics: a population-based prospective cohort study. Prenat Diagn 2020.

[40] Al-Rubaie Z, Askie LM, Ray JG, Hudson HM, Lord SJ. The performance of risk prediction models for pre-eclampsia using routinely collected maternal characteristics and comparison with models that include specialised tests and with clinical guideline decision rules: a systematic review. BJOG 2016; 123:1441-52.

[41] Martinez-Portilla RJ, Caradeux J, Meler E, Lip-Sosa DL, Sotiriadis A, Figueras F. Third-trimester uterine-artery Doppler for prediction of adverse outcome in late small-for-gestational-age fetuses: systematic review and meta-analysis. Ultrasound Obstet Gynecol 2019.

[42] Nilsen RM, Vollset SE, Gjessing HK, Skjaerven R, Melve KK, Schreuder P, et al. Self-selection and bias in a large prospective pregnancy cohort in Norway. Paediatr Perinat Epidemiol 2009;23:597-608. 